\title{
Regional water budgets and hydroclimatic trend variations in Xinjiang from 1951 to 2000
}

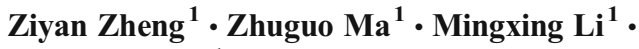 \\ Jiangjiang Xia ${ }^{1}$
}

Received: 23 January 2016 / Accepted: 17 October 2016 / Published online: 3 November 2016

(C) The Author(s) 2016. This article is published with open access at Springerlink.com

\begin{abstract}
Xinjiang is located in arid northwestern China where water cycle has accelerated due to increased precipitation and temperature. However, the regional water budget characteristics vary due to the complex topography and spatial heterogeneities of hydroclimatology. This study uses atmospheric forcing constrained by observation from 90 meteorological stations in Xinjiang as input for the optimized Community Land Model version 3.5 (CLM 3.5) to investigate Xinjiang's regional water budgets from 1951 to 2000 between the northern and southern part divided by the Tianshan Mountain. Results show that precipitation, evapotranspiration and runoff increased in Xinjiang from 1951 to 2000, particularly after the climate shift around 1987, and the net water flux (P-E) gap between North and South Xinjiang was widened. Rapid, intense wetting occurred in North Xinjiang in response to regional climate change, whereas South Xinjiang experienced relatively small changes. North and South Xinjiang exhibited opposite trends in water table depth (WTD), which became shallower in North Xinjiang, particularly after 1987. The WTD in South Xinjiang gradually became deeper. These results suggest that water resources in North Xinjiang are more sensitive to the warmer and wetter climate than South Xinjiang, and the serious water shortage in South Xinjiang did not improve during the second half of the twentieth century.
\end{abstract}

Keywords Climate change $\cdot$ North and South Xinjiang $\cdot$ Water budgets $\cdot$ Hydroclimatic trends

This article is part of a Special Issue on "Mechanism of Decadal-Scale Drought and its Impact on the Ecological Systems and Water Resources over Global Arid and Semi-arid Regions" edited by Zong-Liang Yang and Zhuguo Ma.

\section{Ziyan Zheng}

zhengzy@tea.ac.cn

1 Key Laboratory of Regional Climate-Environment Research for East Asia, Institute of Atmospheric Physics, Chinese Academy of Sciences, Beijing 100029, China 


\section{Introduction}

Global warming has profoundly changed many regional climates over the twentieth century (IPCC 2013). Surface air temperature averaged over China has increased by $0.25^{\circ} \mathrm{C} / 10 \mathrm{yr}$. during the past 50 years, at a rate almost twice the global mean rate of $0.13{ }^{\circ} \mathrm{C} / 10 \mathrm{yr}$. (Ren et al. 2005; Li and Yan 2009; IPCC 2013; Ji et al. 2014). Surface warming and other climate change are known to affect regional water cycle, hydroclimate and water resources (Chen et al. 2007; Zhao et al. 2015; Ljungqvist et al. 2016). Numerous studies have suggested that arid northwestern China are among the most sensitive areas to climate change based on both historical records and future climate projections (Zhang et al. 2004; Li et al. 2012; Yang et al. 2012; Chen et al. 2012, 2014a). Xinjiang covers over $80 \%$ of the northwestern arid area of China; it is featured by complex topography and continental arid climate, which leads to a fragile ecological environment with scarce water supply ( $\mathrm{Li}$ et al. 2013). Water is the critical factor in Xinjiang in keeping the ecosystems function properly, but the regional water cycle in Xinjiang has been affected greatly by climate change (Zhang and Wang 2007; Chen et al. 2015). Thus, investigations of the regional water budget changes over Xinjiang are extremely important not only for understanding its regional water cycle characteristics, but also helping water resources management and sustainability in this region.

Xinjiang refers to a vast area over 1.6 million $\mathrm{km}^{2}$ generally confined within $35^{\circ}-50^{\circ} \mathrm{N}$ and $70^{\circ}-100^{\circ} \mathrm{E}$. The terrain of Xinjiang is dominated by three mountain ranges, namely the Altay, Tianshan and Kunlun Mountains from north to south (Fig. 1). The Junggar Basin, Ili Valley and Tarim Basin are distributed between these massive mountains. Xinjiang also contains the Tarim River and Taklimakan, the largest inland river and desert in China, respectively. Located in the eastern portion is the Turpan Basin, which represents the lowest elevation of the land in China. In addition to the mountains, grasslands comprise the major seasonal land cover in northern Xinjiang (North XJ), but deserts are the dominant land cover in southern Xinjiang (South XJ).

The hydroclimatic characteristics in Xinjiang are very complicated with strong spatial variations due to heterogeneous landscapes and water exchanges among different regions.

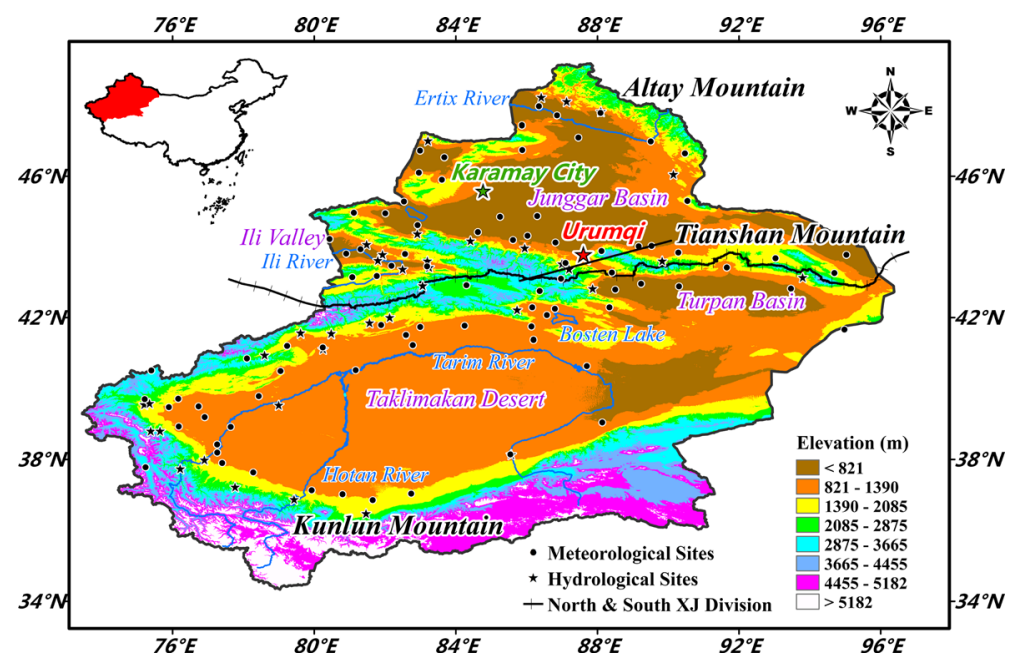

Fig. 1 The schematic topography map of the Xinjiang region 
Annual temperature and precipitation in North $\mathrm{XJ}$ typically range from approximately -4 to $9^{\circ} \mathrm{C}$ and 150 to $200 \mathrm{~mm} / \mathrm{yr}$., respectively. In South XJ, the annual ranges are from 7 to $14{ }^{\circ} \mathrm{C}$ and 25 to $100 \mathrm{~mm} / \mathrm{yr}$. Many studies have examined the impacts of the recent climate change on the water cycle in Xinjiang. Observational studies show that both precipitation and temperature in Xinjiang have increased with large regional variations (He et al. 2003; Ma and Fu 2006; Liu et al. 2009; Li et al. 2012; Jiang et al. 2013; Zheng et al. 2013; Chen et al. 2014a), especially in the different slopes of the Tianshan Mountain (Yuan et al. 2003, 2005; Han et al. 2004). An abrupt change in precipitation over Xinjiang occurred around 1987 (Hu et al. 2002; Shi et al. 2003; Chen et al. 2014b), and the water cycle has accelerated significantly since then (Wang et al. 2003; Chen et al. 2009; Wang et al. 2013; Chen et al. 2014a). These studies suggest that Xinjiang has become warmer and wetter during the recent decades.

In Xinjiang, water budget components are very sensitive to climate change. Li et al. (2013) showed that pan evapotranspiration in Xinjiang decreased significantly from 1960 to 1991, but increased significantly from 1992 to 2007 mainly due to wind speed changes. Mountain glaciers are the main source of runoff in mountainous areas of Xinjiang, but their areas decreased by about $12 \%$ during 1963-2000 due to warmer temperatures (Lan et al. 2007), which lead to more melting of snow and ice (Shen et al. 2013). Chen et al. (2009) analyzed the streamflow of the Tarim River in South XJ, and found increasing trends over its three main sub-basins, although only the streamflow at Aksu River showed a significant increasing trend. These findings indicate that recent climate change have had a large impact on regional water cycle in Xinjiang.

However, the majority of previous studies were mainly based upon field observations and reanalysis datasets. It is still unclear about the interactions of the water exchange among the atmosphere, land surface and soil layers in Xinjiang. Moreover, little effort has been devoted to investigate regional long-term hydroclimatic trends over Xinjiang, and few studies have comprehensively analyzed the regional variations of the these trends considering the dynamical links of the water cycle components.

To address these issues, especially the regional differences in hydroclimatic changes between North and South XJ, we applied the Community Land Model version 3.5 (CLM 3.5) in this study with enhanced hydrological processes to simulate the historical water budgets in Xinjiang from 1951 to 2000 based on observation-constrained atmospheric forcing (Liu et al. 2012). The advanced Geographic Information Systems (GIS) platform was used to derive the water divide of the Tianshan Mountain, which separates North and South XJ. Also, a non-parametric MannKendall test (MKT) method was used to analyze the trends of the water budget components to investigate their response recent climate changes in different parts of Xinjiang. The main objectives of this study are to (i) simulate and analyze the water budget components (e.g. precipitation, evapotranspiration, runoff, soil moisture, etc.) in Xinjiang, (ii) study the hydroclimatic trends of Xinjiang from 1951 to 2000 in response to recent climate change, and (iii) compare and investigate the regional differences of the hydroclimatic trends between North and South XJ.

\section{Model and experimental design}

\subsection{CLM model description and enhancement}

CLM was developed by the National Center for Atmospheric Research (NCAR) to represent land surface processes in the Community Earth System Model (CESM). The CLM version 3.5 
includes a land surface model (LSM) and improved vegetation canopy, snow accumulation, carbon cycle and ET parameterizations (Niu et al. 2005, 2007), which lead to better model performance, particularly at the global scale (Oleson et al. 2008; Wang and Zeng 2011). In addition, enhanced representation of hydrological processes has significantly improved the water cycle simulations (Oleson et al. 2008). To reduce the systematic wet biases in simulated soil moisture, Niu et al. (2011) improved the parameterization with a correction scheme (Eq. (1)) to enhance the water exchanges between soil and underground water. In this study, the soil porosity parameter $\left(f_{\text {mic }}\right)$ is also introduced into soil and underground water exchange scheme in CLM 3.5 in order to reinforce the recharging water from soil to aquifer and to weaken the rising water from aquifer to soil using this equation:

$$
\mathrm{Q}=-K_{b o t} \frac{-Z_{\nabla}-\left(f_{m i c} \varphi_{b o t}-Z_{b o t}\right)}{Z_{\nabla}-Z_{b o t}}
$$

where, $Q$ is the water exchange $(\mathrm{mm})$ between the soil and aquifer, $K_{\mathrm{bot}}$ is the hydraulic conductivity $(\mathrm{mm} / \mathrm{s}), Z_{\nabla}$ and $Z_{\text {bot }}$ are the depths $(\mathrm{mm})$ of the water table and the bottom of the soil layer, respectively, $\psi_{\text {bot }}$ is the matric potential (mm). The parameter $f_{\text {mic }}$ is closely related to soil texture, ranging from 0 to 1 . Specifically, the gravity-caused penetrating water increases as $f_{\text {mic }}$ closes to 0 , conversely the capillary rise water increases as $f_{\text {mic }}$ closes to 1 . The soil textures in this study are assumed to be unchanged over time for simplicity (with spatial distribution), and $f_{\text {mic }}$ is set to 0.5 .

Currently, higher versions of CLM (4.0/4.5) have already offered optimized parameterizations of soil moisture and biogeochemical schemes. However, according to Lawrence et al. (2011), the soil moisture variability still shows negative bias compared with observations. Based upon the previous assessment of the applicability of CLM 3.5 over China ( $\mathrm{Li}$ and Ma 2015; Li et al. 2016), we opted for CLM 3.5 to simulate the long-term hydroclimatic trends over Xinjiang with enhanced hydrological parameterization in this study.

\subsection{Atmospheric forcing data}

Atmospheric forcing is another key factor for accurate land surface modeling (Dickinson et al. 2006; Qian et al. 2006). But there are only sparse weather stations in Xinjiang, especially in its deserts and Gobi (Fig. 1). Nevertheless, several widely used reanalysis or land assimilation products (e.g., NCEP, ERA40 and GLDAS) have large biases for Northwest China (Personal communication with Dr. Fei Chen 2012; with Dr. Yang Hong, 2013). Thus, field observations are still needed for improving the quality of the atmospheric forcing data over our study area. Here, 6-hourly data of precipitation, surface air temperature, wind speed, wind direction, air pressure and relative humidity records from 1951 to 2000 were derived from 90 meteorological stations in Xinjiang (Fig. 1) operated by China Meteorological Administration (CMA). We used these data to generate the atmospheric forcing by Kriging spatial interpolation algorithm. The temporal interpolation of the atmospheric forcing was generated by curve fitting method. Due to the lack of observations, the radiation data were obtained from the Princeton meteorological forcing data (hydrology.princeton.edu/data/, Sheffield et al. 2006). Finally, the new observation-constrained atmospheric forcing data were constructed at $0.5^{\circ}$ grid spacing, 3-h interval for a 50 -year time span from 1951 to 2000 . Several studies have already shown that 
this observation-constrained atmospheric forcing data can significantly improve the land surface simulations over China (Liu et al. 2012; Li and Ma 2015).

\subsection{Experimental design}

The optimized CLM 3.5 was driven offline with the observation-constrained atmospheric forcing data from 1951 to 2000 . The model was first spin-up for 400 years with repeated 50years forcing to allow soil water parameters to reach a sufficient equilibrium. The final 50 years' simulation was used to analyze the surface water budgets in North and South XJ. The general water balance equation can be written as:

$$
\frac{d W}{d t}=P-E-R
$$

where $(d W / d t)$ is the terrestrial water storage (TWS) variations, which equals the precipitation $(P)$ minus the actual evapotranspiration $(E)$ and runoff $(R)$.

The rank-based MKT (Mann 1945; Kendall 1975) was used to detect hydroclimatic trends based on a linear regression analysis. The MKT method is a nonparametric and commonly used method that can validate the significant level of monotonic trends in hydrometeorological time series (Yue and Wang 2002; Geng et al. 2016).

Regional difference analyses in North and South XJ require accurate basin division procedures. Here, the ArcGIS-Desktop 10.1 platform (www.esri.com) and Arc-Hydro extension tools (resources.arcgis.com/en/communities/hydro/) were utilized to extract the Tianshan Mountain water divide, which separates North and South XJ. Arc-Hydro uses a digital elevation model (DEM) with $90 \mathrm{~m}$ horizontal spacing derived from the Shuttle Radar Topography Mission (SRTM, lta.cr.usgs.gov/SRTM) (Jarvis et al. 2008). All of the Xinjiang catchments were then delineated and the Tianshan Mountain water divide polylines were used as the boundaries of North and South XJ (Fig. 1).

\section{Results and discussion}

\subsection{Surface water budgets}

Figure 2 shows the spatially-averaged annual precipitation and temperature (interpolated from station observations), and CLM-simulated evapotranspiration, runoff, TWS, P-E time series for whole Xinjiang, North XJ and South XJ from 1951 to 2000. The associated linear trends are all summarized in Table 1. Annual precipitation in Xinjiang shows an obvious increase during the second half of the twentieth century. It increased by an average rate of $4.9 \mathrm{~mm} /$ $10 \mathrm{yr}$. This increasing rate reaches $4.6 \mathrm{~mm} / 10 \mathrm{yr}$. in South XJ and $5.7 \mathrm{~mm} / 10 \mathrm{yr}$. in North XJ. As surface temperature and precipitation increase, the simulated evapotranspiration rate over Xinjiang also increases by 3.9, 2.7 and $4.3 \mathrm{~mm} / 10$ yr. for whole Xinjiang, North XJ and South $\mathrm{XJ}$, respectively (Fig. 2b).

Due to the precipitation increases, the simulated runoff in North XJ also increased by $3.0 \mathrm{~mm} / 10 \mathrm{yr}$, while it remained relatively constant in South XJ. Therefore, runoff changes are negligible for surface water budget changes in South XJ. The whole Xinjiang runoff increased by $0.9 / 10$ yr. during 1951-2000. This runoff increase is due to increased precipitation and warmer temperatures (Fig. 2f), which can cause more melting of snow and glacier ice (Chen 
a

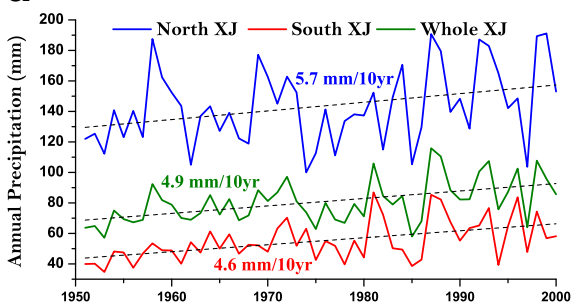

b

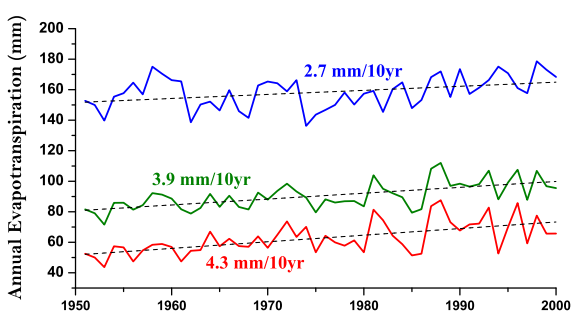

C

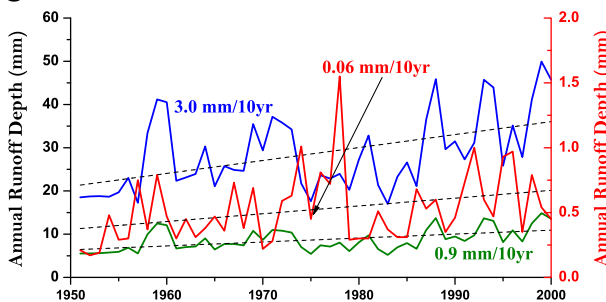

d

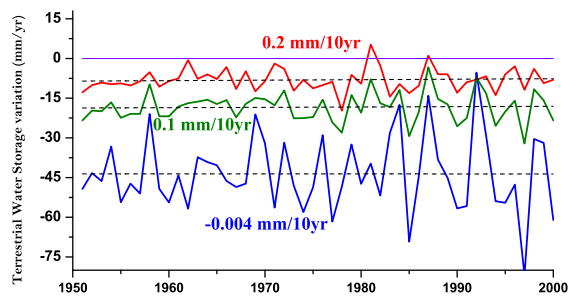

e

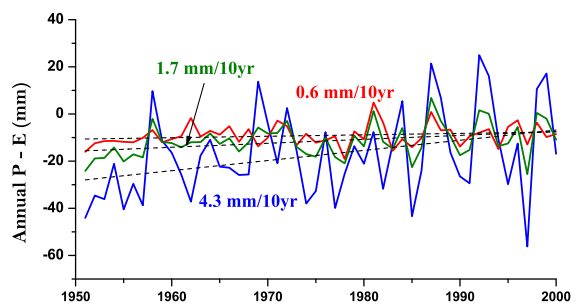

f

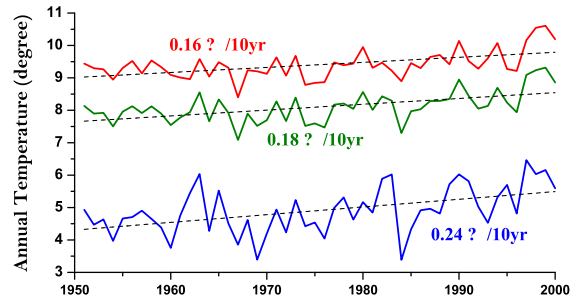

Fig. 2 Annual a precipitation from observation-constrained forcing; $\mathbf{b}$ evapotranspiration; $\mathbf{c}$ runoff; $\mathbf{d}$ TWS variation; e precipitation minus evapotranspiration (P-E) and $\mathbf{f}$ temperature time series Xinjiang (including North and South XJ) simulated by CLM 3.5

et al. 2014a). These factors cause the North XJ runoff rate increased rapidly after the 1987 climate shift when both precipitation and temperature increased substantially over Xinjiang (Fig. 2a-b). In addition, TWS and P-E also exhibited larger inter-annual variations after 1987 than before (Fig. 2d-e).

These results indicate that the water input (P) increased faster in North XJ than in South XJ, but for the water consumption (E), the increasing rate was larger in South XJ than in North XJ due to warmer temperature As a result, the increment of P-E flux in North XJ was as high as $4.3 \mathrm{~mm} / 10$ yr., more than 7 times larger than in South XJ (Fig. 2e). Also, the gap of P-E between North XJ and South XJ increased from 1951 to 2000. The results further suggest that North XJ water budget components are more sensitive to climate change than South XJ, where the components are characterized by gradual trends due to the vast desert environment.

\subsection{Spatial distributions of trends}

Figures 3 show the linear trend maps for the water budget components and temperature over Xinjiang. We can see precipitation increased over nearly entire Xinjiang from 1951 to 2000 , with the largest increase (over $15 \mathrm{~mm} / 10 \mathrm{yr}$ ) in the Junggar Basin, and decreased in the eastern 
Table 1 Annual trends from 1951 to 2000 of the water budget components and temperature averaged over Xinjiang

\begin{tabular}{|c|c|c|c|c|}
\hline Variables & $\begin{array}{l}\text { Area mean } \\
(\mathrm{mm})\end{array}$ & $\begin{array}{l}\text { Linear trend } \\
(\mathrm{mm} / 10 \mathrm{yr})\end{array}$ & $\begin{array}{l}\text { Standard error } \\
(\mathrm{mm} / 10 \mathrm{yr})\end{array}$ & $\begin{array}{l}\text { Significance level } \\
\text { ( } p \text { value) }\end{array}$ \\
\hline Precipitation & 80.7 & 4.9 & 1.2 & $<0.01$ \\
\hline Precipitation in North XJ & 143.4 & 5.7 & 2.4 & 0.02 \\
\hline Precipitation in South XJ & 55.1 & 4.6 & 1.1 & $<0.01$ \\
\hline Evapotranspiration & 90.4 & 3.9 & 0.7 & $<0.01$ \\
\hline Evapotranspiration in North $\mathrm{XJ}$ & 158.4 & 2.7 & 1.0 & $<0.01$ \\
\hline Evapotranspiration in South XJ & 62.7 & 4.3 & 0.8 & $<0.01$ \\
\hline$(P-E)^{a}$ & -11.51 & 1.7 & 0.7 & 0.01 \\
\hline$(\mathrm{P}-\mathrm{E})$ in North $\mathrm{XJ}$ & -17.38 & 4.3 & 1.8 & 0.02 \\
\hline$(P-E)$ in South $X J$ & -9.12 & 0.6 & 0.4 & 0.17 \\
\hline Runoff & 8.7 & 0.09 & 0.2 & $<0.01$ \\
\hline Runoff in North XJ & 28.7 & 3.0 & 0.8 & $<0.01$ \\
\hline Runoff in South XJ & 0.5 & 0.06 & 0.0 & 0.02 \\
\hline Snowmelt & 15.0 & 0.8 & 0.4 & 0.03 \\
\hline Snowmelt in North XJ & 40.2 & 1.7 & 1.0 & 0.1 \\
\hline Snowmelt in South XJ & 6.8 & 0.5 & 0.2 & 0.06 \\
\hline TWS change $(d W / d t)$ & -18.4 & 0.1 & 0.6 & $>0.1$ \\
\hline TWS change in North XJ & -43.6 & -0.004 & 1.4 & $>0.1$ \\
\hline TWS change in South XJ & -8.1 & 0.2 & 0.4 & $>0.1$ \\
\hline Shallow Soil Moisture (SSM) & 111.3 & 2.3 & 0.2 & $<0.01$ \\
\hline SSM in North XJ & 143.0 & 2.4 & 0.3 & $<0.01$ \\
\hline SSM in South XJ & 98.1 & 2.1 & 0.2 & $<0.01$ \\
\hline Deep Soil Moisture (DSM) & 544.5 & 7.5 & 0.8 & $<0.01$ \\
\hline DSM in North XJ & 746.7 & 15.9 & 1.8 & $<0.01$ \\
\hline DSM in South XJ & 468.2 & 3.3 & 0.6 & $<0.01$ \\
\hline Temperature $\left({ }^{\circ} \mathrm{C} / 10 \mathrm{yr}\right)$ & 8.10 & 0.18 & 0.039 & $<0.01$ \\
\hline Temperature in North $\mathrm{XJ}\left({ }^{\circ} \mathrm{C} / 10 \mathrm{yr}\right)$ & 4.91 & 0.24 & 0.063 & $<0.01$ \\
\hline Temperature in South $\mathrm{XJ}\left({ }^{\circ} \mathrm{C} / 10 \mathrm{yr}\right)$ & 9.41 & 0.16 & 0.037 & $<0.01$ \\
\hline
\end{tabular}

${ }^{\mathrm{a}}(\mathrm{P}-\mathrm{E})$ indicates annual precipitation minus annual evapotranspiration

portion of the Ili Valley and the nearby Karamay city (Fig. 3a). Evapotranspiration also increased over most of Xinjiang and the change patterns generally mimic the precipitation trend distribution, but with smaller magnitudes (Fig. 3b). In the Ili Valley, precipitation increased while evapotranspiration decreased, leading to large runoff increase in this region (Fig. 3a-c). Runoff decreased in portions of South XJ due to the much smaller net water flux (P-E) and rapid infiltration in the desert. In North XJ, the maximum trend value of P-E flux can be up to $14 \mathrm{~mm} / 10 \mathrm{yr}$., much higher than in South XJ (Fig. 3e). Spatial variations in TWS trends are small over most Xinjiang, with wet conditions causing TWS to increase slightly in portions of the Taklimakan Desert. As seen in Fig. 3, the trends for all of the water budget components are larger in North XJ than in South XJ, with the highest trends distributed in North XJ. Thus, the acceleration of the water cycle in North XJ is much stronger than in South XJ. 

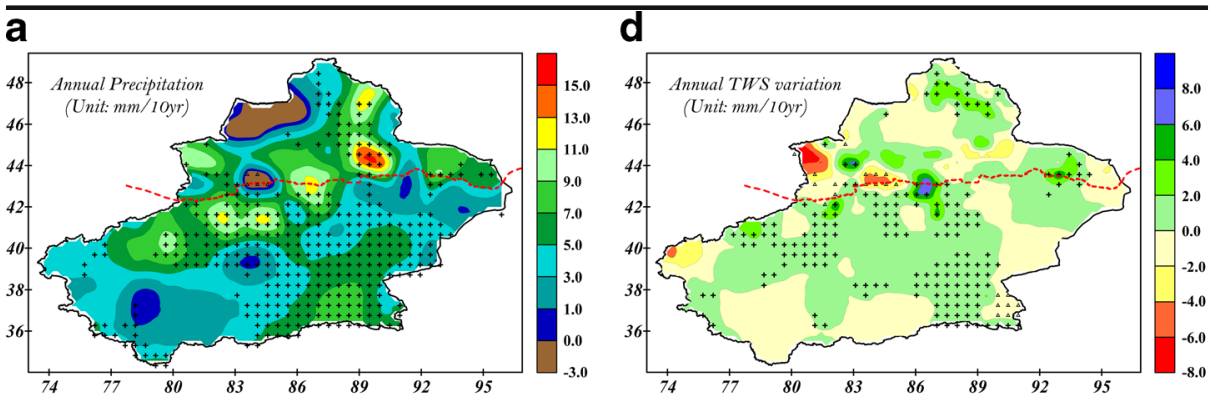

b

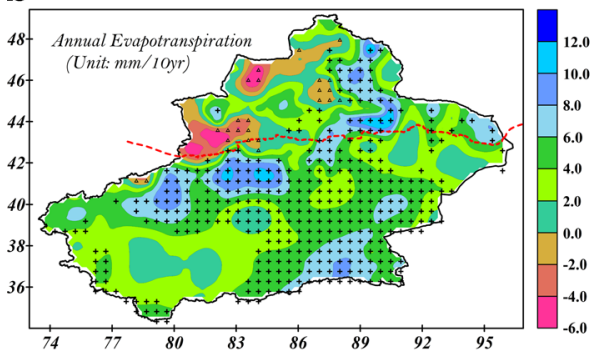

e

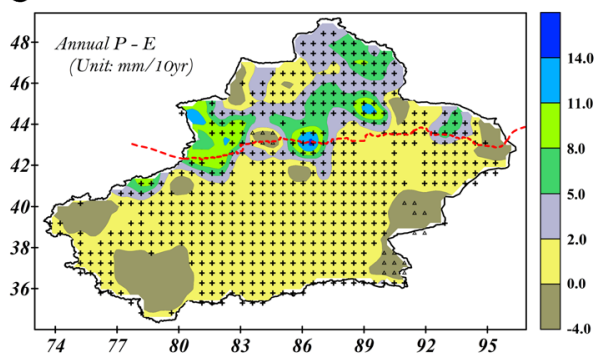

C

f
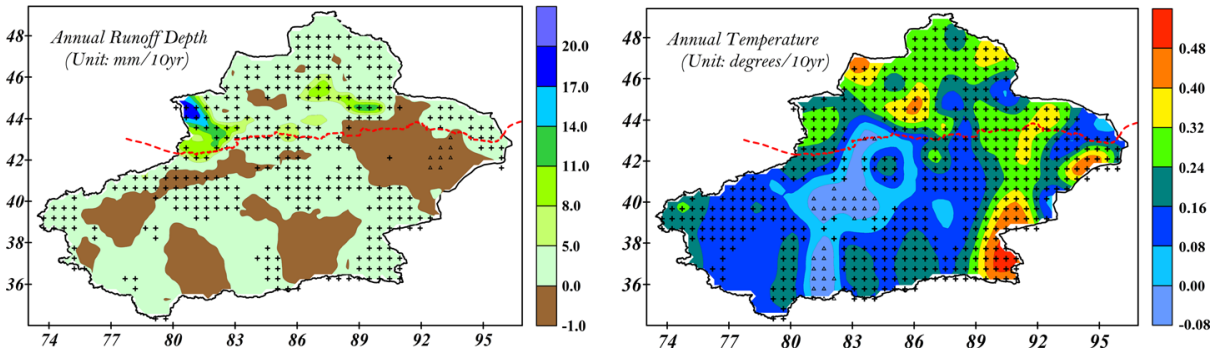

Fig. 3 Spatial distributions of the annual linear trends from 1951 to 2000 for precipitation (a); CLM 3.5 simulated evapotranspiration (b), runoff $(\mathbf{c})$, TWS variation $(\mathbf{d})$, precipitation minus evapotranspiration $(\mathrm{P}-\mathrm{E})(\mathbf{e})$ and temperature (f) using Mann-Kendall algorithm. The symbols represent statistically significant increases ("+") or decreases (" $\Delta$ ") (0.01 significance level) respectively, and the red dash line represents the boundary of North and South XJ

\subsection{Soil moisture and water table depth}

The total soil depth in CLM 3.5 is $3.433 \mathrm{~m}$, and the soil column is divided into 10 layers with different thicknesses. In this study, the top 7 layers $(0.62 \mathrm{~m})$ are considered as "shallow" soil layers, while the rest 3 lower layers $(2.813 \mathrm{~m})$ are deemed "deep" soil layers. Figure 4a-b shows the trend distributions of simulated soil water content in the shallow and deep layers. These results show that soil moisture in the shallow layer increased over entire Xinjiang, especially in the Junggar Basin, eastern North XJ and the southern slope of the Tianshan Mountain, with the largest increases at the mountainous areas along Tianshan and Altay Mountains (Fig. 4a). Soil moisture trends are more spatially heterogeneous in the deep layer (Fig. 4b). In North XJ, the deep-layer soil moisture shows strong positive trends, whereas the negative trends are seen in the central Taklimakan Desert and the Turpan Basin in South XJ. 
The soil moisture trend patterns are closely related to the precipitation and temperature distributions and landscape heterogeneities over the entire region. Overall, North XJ experienced larger precipitation increases, while larger loss of water occurred in South XJ due to larger evapotranspiration trends (Fig. 2b). In general, the large desert area in South XJ exhibited limited ability to store and retains water in deep soils.

Figures $4 \mathrm{c}-\mathrm{d}$ shows the temporal variations of soil moisture in the shallow and deep layers. The results suggest that the soil moisture in Xinjiang generally increased in both layers from 1951 to 2000. Positive anomalies are particularly common after the climate shift around 1987, which coincides with the precipitation and temperature increases (Fig. 2a-b). The soil moisture response to warm-wet climate trend during 1951-2000 is larger in North XJ than in South. North XJ also displays larger inter-annual variability in soil moisture. Although precipitation increased over entire Xinjiang, the excess water did not infiltrate into the deep soil layers over South XJ. Therefore, the soil moisture in the deep layer of South XJ increased minimally compared with the soil moisture increase in the deep layer in North XJ.

Groundwater is an important factor for land-atmosphere interactions (Niu et al. 2007), and it can even provide water for evapotranspiration in arid regions (Gutowski et al. 2002). In this study, regional groundwater variations were simulated using the water table depth (WTD) as a long term indicator and plotted in Fig. 5. In Fig. 5a we can see the WTD trends are highly heterogeneous over Xinjiang, with significant reduction (i.e., WTD becomes shallower) over North XJ, except in the western Junggar Basin. The Altay and Ili Valleys exhibited the highest rate of increase in the WTD at approximately $0.2 \mathrm{~m} / 10 \mathrm{yr}$. The WTD trend in South XJ show positive trends (the WTD becomes deeper) and is opposite to the trend in North XJ, except on small portions of the southern slope of the Tianshan Mountain. A clear WTD boundary can be

a

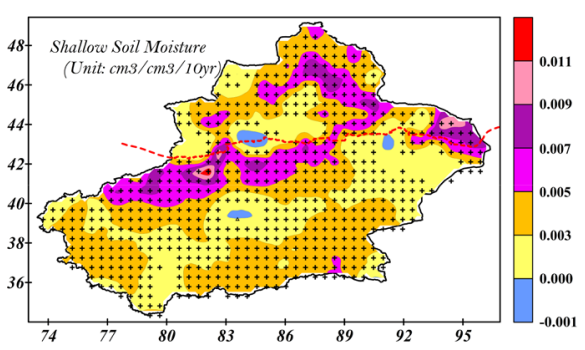

b

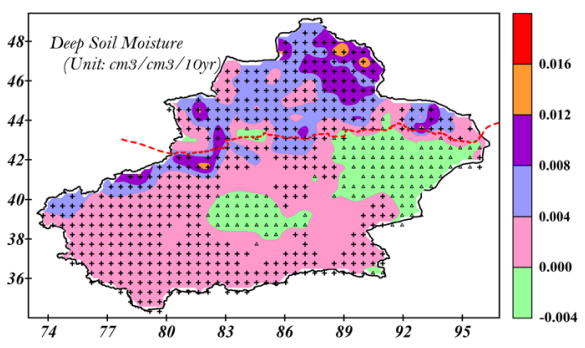

C

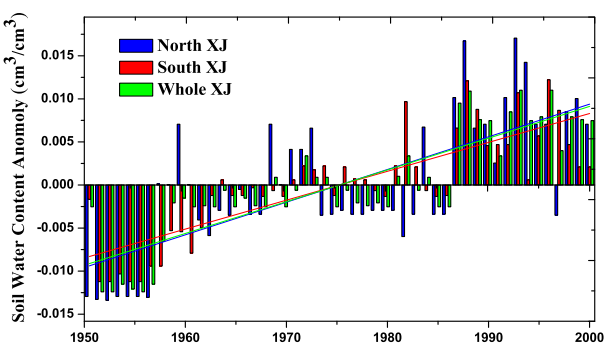

d

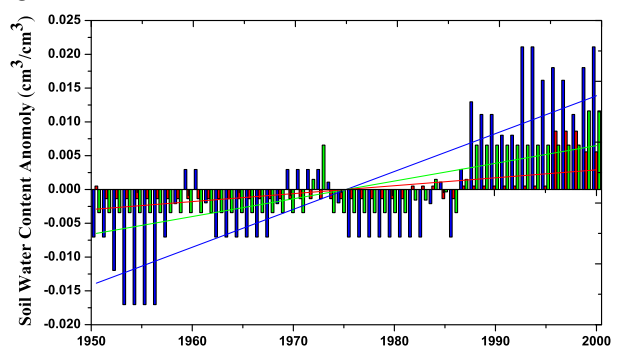

Fig. 4 CLM 3.5-simulated soil moisture content for the spatial distributions of the annual linear trends in a shallow layers $(0-0.62 \mathrm{~m})$ and $\mathbf{b}$ deep layers $(0.62-3.433 \mathrm{~m})$, the symbols and dash red line are same as Fig. 3; and the temporal anomaly soil moisture series in $\mathbf{c}$ shallow and $\mathbf{d}$ deep layers 
seen in Fig. 5a as the trend shifts from positive to negative. This boundary is coincident with the divide between North and South XJ.

Figure $5 \mathrm{~b}$ shows that the WTD changes for North and South XJ are very different. The WTD in North XJ exhibited apparent decadal variations in response to recent climate change, becoming increasingly shallower after 1987. However, South XJ WTD slowly deepened despite the precipitation increases (Fig. 2a). One possible reason is that in arid regions, especially in the deserts, the groundwater is little recharged by precipitation because of the deep WTD and strong evapotranspiration, this would lead to a decoupling between the precipitation and WTD trends in long-term scale in South XJ. The simulated WTD changes over Xinjiang are consistent with previous studies (e.g., Xia et al. 1991), which indicate that the water content stored in soil and underground have different sources in North and South XJ. Xia et al. (1991) showed that the soil and subsurface water in Gurbantünggüt Desert (the main part of the Junggar Basin in North XJ) is derived mainly from precipitation, while in Takilimakan Desert are mainly recharged by ground water (i.e., little infiltration from precipitation). This is the reason why the WTD in North XJ responds to the increased precipitation

a

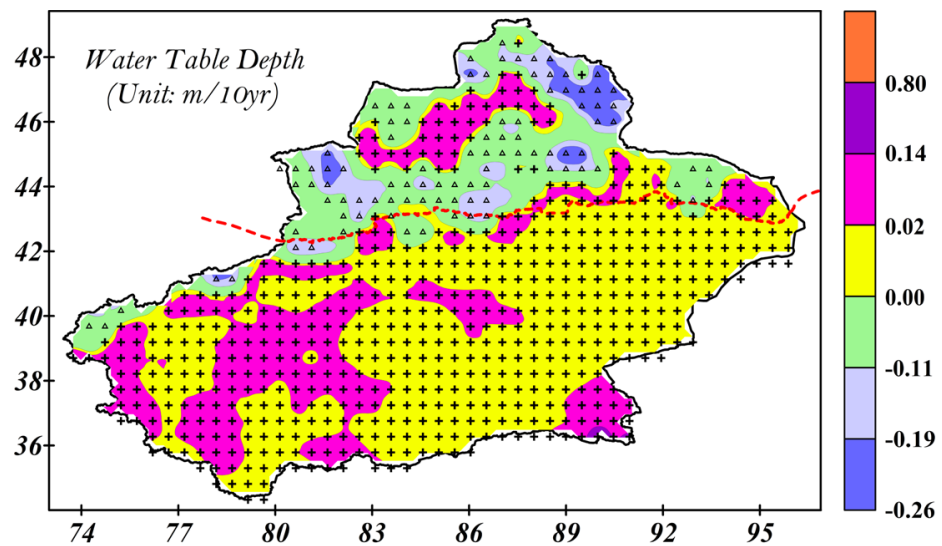

b

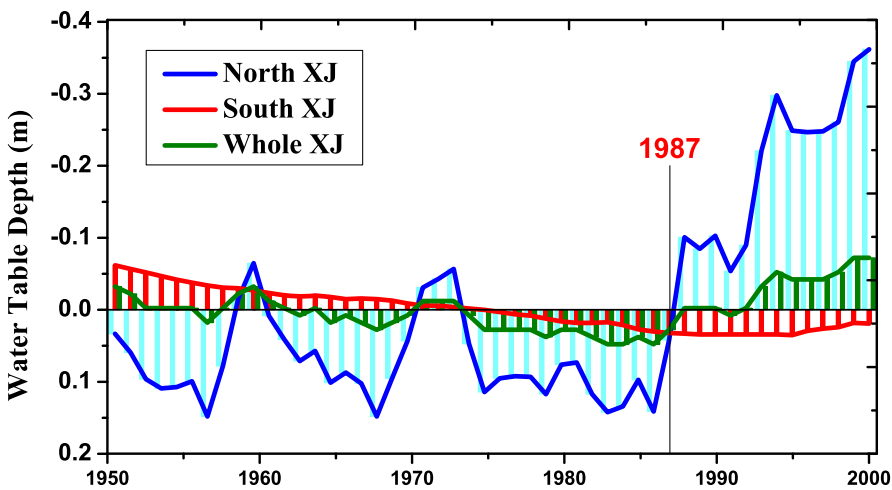

Fig. 5 CLM simulated WTD in Xinjiang a spatial trend distributions, the symbols and dash red line are same as Fig. 3; and b temporal variations, the larger negative/positive anomalies indicate the shallower/deeper WTD 
more closely than in South XJ. Although the climate in Xinjiang showed a warm-wet trend in the last few decades, the groundwater outlook in South XJ remains vulnerable.

\section{Summary}

Xinjiang is the largest area with arid climate in inland China. Recent climate change, especially the shift change around 1987 has affected Xinjiang's regional water budget in various aspects. This study used the optimized CLM 3.5 forced with observation-constrained atmospheric forcing to investigate water budget changes and compare the hydroclimatic trends between North and South XJ. The divide of North and South XJ was represented by the water divide formed by the Tianshan Mountain. Trends in water budget components were then analyzed using the MKT method.

Xinjiang experienced warming and wetting from 1951 to 2000. Annual precipitation and evapotranspiration increased across whole Xinjiang. The trends in North XJ were more spatially heterogeneous than in South XJ. Nearly all the largest water budget trends occurred in North XJ, for both increases and decreases. Regionally averaged precipitation increased faster in North XJ than in South XJ (where it has a lower annual precipitation and drier climate than North XJ), whereas evapotranspiration increased faster in South XJ than in North XJ. This worsened net water flux (P-E) gap between North and South XJ during the second half of the twentieth century.

Significant increases in precipitation and snowmelt caused runoff to increase much faster in North XJ than in South XJ, where runoff remained relatively constant. The total water storage exhibited no significant trends across Xinjiang. Due to increased precipitation variations, the inter-annual terrestrial water storage (TWS) variations in North XJ became larger after 1987 than before.

Soil moisture and water table depth (WTD) trends were non-uniform across Xinjiang. The shallow layer $(0-0.62 \mathrm{~m})$ soil moisture increased across Xinjiang, especially in mountainous areas. Changes in the deep layer $(0.62-3.433 \mathrm{~m})$ soil moisture were heterogeneous, with significant increases in North XJ but with small changes in South XJ. Both the shallow and deep layer soil moisture trends were affected by the 1987 climate shift in North XJ, while the deep layer in South XJ displayed no response to the climate change. Moreover, the WTD trend showed opposite changes in North and South XJ. The WTD in North XJ became shallower after the climate shift in 1987, but the WTD in South XJ became deeper and was not affected by the increases in temperature and precipitation in the recent decades.

These results of this study indicate the water shortage in Xinjiang, especially South $\mathrm{XJ}$, have not improved fundamentally despite the increases in temperature and precipitation during 1951-2000. The TWS variations showed no significant increases and ground water deletion continued over large areas of South XJ, as suggested by the deepening WTD there.

Besides the climate-induced changes investigated here, the water budgets in Xinjiang are also affected directly by human activities in recent years (Chen and Xu 2004; Li et al. 2014). For example, afforestation and irrigation have considerable impacts on evaporation and soil moisture in arid regions like Xinjiang. Moreover, the modeling study presented here has several limitations. One problem is the simulated WTD cannot go deeper in this very arid area due to the relative coarse spatial resolution. And uncertainties exist within 
the atmospheric forcing data, which were constrained with sparse observations. Moreover, quantitative investigations to distinguish the impact of climate change and other human activities on water budgets and the hydroclimate over Xinjiang are still needed in the future.

Acknowledgments This study is jointly sponsored by the National Basic Research Program of China (2012CB956201), the National Natural Science Foundation of China (41605085), the China Special Fund for Meteorological Research in the Public Interest (GYHY201506001-1) and the Opening Fund of Key Laboratory for Land Surface Process and Climate Change in Cold and Arid Regions of Chinese Academy of Sciences (LPCC201303). We also appreciate detailed comments provided and encouragement made by the reviewers, the Editor and the associate Editor.

Open Access This article is distributed under the terms of the Creative Commons Attribution 4.0 International License (http://creativecommons.org/licenses/by/4.0/), which permits unrestricted use, distribution, and reproduction in any medium, provided you give appropriate credit to the original author(s) and the source, provide a link to the Creative Commons license, and indicate if changes were made.

\section{References}

Chen YN, Xu ZX (2004) The possible impact of global climate change on water resources in the Tarim River basin. Science in China: Series D 34(11):1047-1053

Chen YN, Li WH, Xu CC, Hao XM (2007) Effects of climate change on water resources in Tarim River basin, Northwest China. J Environ Sci 19(4):488-493

Chen YN, Xu CC, Hao XM, Li WH, Chen YP, Zhu CG, Ye ZX (2009) Fifty-year climate change and its effect on annual runoff in the Tarim River basin, China. Quat Int 208(1):53-61

Chen YN, Yang Q, Luo Y et al (2012) Ponder on the issue of water resources in the arid region of Northwest China. Arid Land Geography (in Chinese) 35(1):1-9

Chen YN, Li Z, Fan YT, Wang HJ, Fang GH (2014a) Research progress on the impact of climate change on water resources in the arid region of Northwest China. Acta Geographica Sinica (in Chinese) 69(9):1295-1304

Chen YN, Deng HJ, Li BF et al (2014b) Abrupt change of temperature and precipitation extremes in the arid region of Northwest China. Quat Int 336:35-43

Chen YN, Li Z, Fan Y et al (2015) Progress and prospects of climate change impacts on hydrology in the arid region of Northwest China. Environ Res 139:11-19

Dickinson RE, Oleson KW, Bonan G et al (2006) The community land model and its climate statistics as a component of the community climate system model. J Clim 19:2302-2324

Geng, Q., P. Wu, and X. Zhao (2016) Spatial and temporal trends in climatic variables in arid areas of Northwest China. International Journal of Climatology.

Gutowski, W. J., Vörösmarty, C. J., Person, M., et al. (2002) A Coupled Land-Atmosphere Simulation Program (CLASP): Calibration and validation. J. Geophys. Res., 107(D16): ACL 3-1-ACL 3-17.

Han TD, Ding YJ, Ye BS, Xie CW (2004) Precipitation variations on the southern and northern slopes of the Tianger range in Tianshan Mountains. Chinese Journal of Glaciology and Geocryology 26(6):761-766

He Q, Yang Q, Li HJ (2003) Variations of air temperature, precipitation and sand-dust weather in Xinjiang in past 40 years. Chinese Journal of Glaciology and Geocryology 25(4):423-427

Hu RY, Jiang FQ, Wang YJ, Fan ZL (2002) A study on signals and effects of climatic pattern change from warmdry to warm-wet in Xinjiang. Arid Land geography (in Chinese) 25(3):194-200

IPCC. (2013): Observations: Atmosphere and Surface. In: Climate Change 2013: The Physical Science Basis. Contribution of Working Group I to the Fifth Assessment Report of the Intergovernmental Panel on Climate Change. Chapter 2.4: 187-189 pp. Cambridge University Press, Cambridge, United Kingdom and New York, NY, USA.

Jarvis, A., H. I. Reuter, A. Nelson and E. Guevara (2008) Hole-filled SRTM for the globe Version 4, available from the CGIAR-CSI SRTM 90 m Database (srtm.csi.cgiar.org)

Ji F, Wu ZH, Huang JP et al (2014) Evolution of land surface air temperature trend. Nat Clim Chang 4(6):462466. doi:10.1038/NCLIMATE2223

Jiang FQ, Hu RJ, Wang SP et al (2013) Trends of precipitation extremes during 1960-2008 in Xinjiang, the Northwest China. Theor Appl Climatol 111(1-2):133-148

Kendall MG (1975) Rank correlation methods, 4th edn. Charles Griffin, London 
Lan YC, Shen YP, Wu SF et al (2007) Changes of the glaciers and the glacier water resources in the typical river basins on the north and south slopes of the Tianshan Mountain since 1960s. Journal of Arid Land Resources and Environment (in Chinese) 21(11):1-8

Lawrence DM, Oleson KW, Flanner MG et al (2011) Parameterization improvements and functional and structural advances in version 4 of the community land model. Journal of Advances in Modeling Earth Systems 3(1). doi:10.1029/2011MS000045

Li MX, Ma ZG (2015) Soil moisture drought detection and multi-temporal variability across China. Sci China Earth Sci 58(10):1798-1813. doi:10.1007/s11430-015-5076-8

Li Z, Yan ZW (2009) Homogenized daily mean/maximum/minimum temperature series for China from 1960 to 2008. Atmos Oceanic Sci Lett 2:237-243

Li LH, Bai L, Yao YN, Yang Q (2012) Projection of climate change in Xinjiang under IPCC SRES. Resource Science (in Chinese) 34(4):602-612

Li Z, Chen YN, Shen YJ et al (2013) Analysis of changing pan evaporation in the arid region of Northwest China. Water Resour Res 49(4):2205-2212

Li S, Tang Q, Lei J et al (2014) An overview of non-conventional water resource utilization technologies for biological sand control in Xinjiang, Northwest China. Environmental Earth Sciences 73(2):873-885

Li, M. X., Z. G. Ma and M. X. Lv (2016) Variability of modeled runoff over China and its links to climate change. Climatic Change, 1-13, doi:10.1007/s10584-015-1593-x.

Liu B, Feng JM, Ma ZG et al (2009) Characteristics of climate changes in Xinjiang from 1960 to 2005. Climatic and Environmental Research (in Chinese) 14(4):414-426

Liu B, Ma ZG, Feng JM (2012) Simulation of land surface water and energy budget from 1960 to 2004 in Xinjiang, China part I: development of forcing data set with observational meteorological data. Chinese Journal of Desert Research 32(2):491-502

Ljungqvist FC, Krusic PJ, Sundqvist HS et al (2016) Northern hemisphere hydroclimate variability over the past twelve centuries. Nature 532(7597):94-98

Ma ZG, Fu CB (2006) Some evidence of drying trend over northern China from 1951 to 2004. Chin Sci Bull 51(20):2913-2925

Mann HB (1945) Non-parametric tests against trend. Econometrica 13:163-171

Niu GY, Yang ZL, Dickinson RE, Gulden LE (2005) A simple TOPMODEL-based runoff parameterization (SIMTOP) for use in global climate models. J Geophys Res 110(D21):D21106

Niu GY, Yang ZL, Dickinson RE, Gulden LE, Su H (2007) Development of a simple groundwater model for use in climate models and evaluation with gravity recovery and climate experiment data. J Geophys Res 112(D7):D07103

Niu, G. Y., Z. L. Yang, Mitchell, K. E., et al. (2011) The community Noah land surface model with multiparameterization options (Noah-MP): 1. Model description and evaluation with local-scale measurements. J. Geophys. Res., 116: D12109, doi:10.1029/2010JD015139.

Oleson KW, Niu GY, Yang ZL et al (2008) Improvements to the community land model and their impact on the hydrological cycle. J Geophys Res-Biogeosci 113. doi:10.1029/2007JG000563

Qian TT, Dai AG, Trenberth KE et al (2006) Simulation of global land surface conditions from 1948 to 2004. Part I: forcing data and evaluations. J Hydrometeorol 7:953-975

Ren GY, Chu ZY, Zhou YQ et al (2005) Recent progresses in studies of regional temperature changes in China. Climatic and Environmental Research (in Chinese) 10(4):701-716

Sheffield J, Goteti G, Wood EF (2006) Development of a 50-year high-resolution global dataset of meteorological forcings for land surface modeling. J Clim 19:3088-3111. doi:10.1175/JCLI3790.1

Shen YP, Su HC, Wang GY et al (2013) The responses of glaciers and snow cover to climate change in Xinjiang (I): hydrological effect. J Glaciol Geocryol 35(3):513-527

Shi YF, Shen YP, Li DL et al (2003) Discussion on the present climate change from warm-dry to warm-wet in Northwest China. Quaternary Sciences 23(2):152-164

Wang AH, Zeng XB (2011) Sensitivities of terrestrial water cycle simulations to the variations of precipitation and air temperature in China. J Geophys Res 116:D02107. doi:10.1029/2010JD014659

Wang SR, Zheng SH, Chen L (2003) Studies on impacts of climate change on water cycle and water resources in Northwest China. Climatic and Environmental Research (in Chinese) 8(1):43-51

Wang BL, Zhang MJ, L. J et al (2013) Changes in extreme events of temperature and precipitation over Xinjiang, Northwest China, during 1960-2009. Quat Int 298:141-151

Xia XC, Li CS, Zhou XJ et al (1991) Desertification and control of blown sand disasters in Xinjiang. Science Press, Beijing

Yang YH, Chen YN, Li WH et al (2012) Climatic change of inland river basin in arid area: a case study in northern Xinjiang, China. Theor Appl Climatol 107(1/2):143-154

Yuan YJ, He Q, Mu GJ (2003) Summer precipitation change for recent 40 Years in the Tianshan Mountains and compared with southern and northern Xinjiang regions. Chinese Journal of Glaciology and Geocryology 25(3): 331-335 
Yuan YJ, Xie GH, Wei WS, Zhang JB (2005) Similarities and differences between summer temperature changes in Tianshan mountainous region and southern and northern Xinjiang. Meteorological Science and Technology (in Chinese) 33(2):152-155

Yue S, Wang CY (2002) Applicability of prewhitening to eliminate the influence of serial correlation on the Mann-Kendall test. Water Resour. Res. 38(6):1068. doi:10.1029/2001WR000861

Zhang Q, Wang S (2007) Processes of water transfer over land surface in arid and semi-arid region of China. Arid Meteorology (in Chinese) 25(2):1-4

Zhang JY, Dong WJ, Yu YQ, Feng JM (2004) A prediction of trend of the future climate change in the western China. Climatic and Environmental Research (in Chinese) 9(2):342-349

Zhao J, Huang Q, Chang J et al (2015) Analysis of temporal and spatial trends of hydro-climatic variables in the Wei River basin. Environ Res 139:55-64

Zheng JY, Bian JJ, Ge QS et al (2013) The climate regionalization in China for 1981-2010 (in Chinese). Chin Sci Bull (Chin Ver) 58(30):3088-3099. doi:10.1360/972012-1491 